\title{
Endoscopic retrieval of intrauterine contraceptive device from urinary bladder
}

\section{Pradnya Rajendra Changede*, Shubhrita Sheokumar Gupta, Niranjan Narayanrao Chavan}

Department of Obstetrics and Gynecology, Lokmanya Tilak Municipal Medical College and General Hospital, Sion, Mumbai, Maharashtra, India

Received: 22 July 2015

Revised: 21 August 2015

Accepted: 29 August 2015

\section{*Correspondence:}

Dr. Pradnya Rajendra Changede,

E-mail: pradnyachangede@gmail.com

Copyright: $\odot$ the author(s), publisher and licensee Medip Academy. This is an open-access article distributed under the terms of the Creative Commons Attribution Non-Commercial License, which permits unrestricted non-commercial use, distribution, and reproduction in any medium, provided the original work is properly cited.

\begin{abstract}
Contraception is the need of hour in a developing country like India. Intrauterine contraceptive devices (IUCDs) are amongst the most frequently used spacing method of contraception. The patients with misplaced IUCDs may present with 'lost strings', pregnancies or they may remain asymptomatic. The case report describes successful endoscopic retrieval of intrauterine contraceptive device from urinary bladder. X-ray, ultrasound and computed tomography (CT) urography of the pelvis showed IUCD to be lying outside the uterus and on cystoscopy IUCD was removed from urinary bladder.
\end{abstract}

Keywords: Intrauterine contraceptive device, Urinary bladder, Computed tomography urography, Cystoscopy

\section{INTRODUCTION}

The intrauterine contraceptive device became available from 1909 when Dr. Richter of Walsenburg described the method. Intrauterine contraceptive devices (IUCD) has been described as the most effective reversible from of contraception available. There are 3 types of IUCD: inert, copper bearing and hormone releasing. IUCDs are indicated in any woman who requests for the method, and has no contra-indication to its use. ${ }^{1}$ Common contraindications to its use are a history of pregnancy, pelvic inflammatory disease, fibroids, congenital abnormality of the uterus, tumours. Complications include expulsion, displacement, pelvic inflammatory disease, perforation, bleeding and ectopic pregnancy. An intrauterine device is inserted into a woman's uterus through her vagina. The intrauterine device normally stays within the uterus. Rarely, the intrauterine device may perforate uterus and rest in the adjoining viscera. This is probably due to a mistake during insertion and not due to slow movement through the wall of the uterus. The transuterine and the transvesical migration of an IUCD is a rare complication. The possibility of an IUCD placement, directly into the urinary bladder, could not be ruled out as in our case.

\section{CASE REPORT}

21 years old woman married since 8 years, para3, living3, all full term normal deliveries presented to tertiary care hospital with the complaint of pain in lower abdomen and dysuria since last 1 year. According to the patient, she had IUCD insertion 1 year back in a peripheral hospital. At the time of insertion patient had severe excruciating pain in lower abdomen with nausea and vomiting. Immediately post insertion she complained of increased frequency of urination and dysuria. She reported next day to the respective hospital where per speculum examination revealed non-visualization of IUCD threads. She was counselled that there may be a possibility of vaginal expulsion of IUCD. The following year patient had regular menstrual periods but she had constant lower 
abdominal pain and urinary symptoms. She reported to our hospital due to increased severity of symptoms i.e. dysuria and abdominal pain since 8 days.

On abdominal examination she had mild tenderness in the hypogastrium and on pelvic examination no thread of IUCD was seen and felt. Uterus size was normal, retroverted and no adnexal pathology was detected. On investigation urine examination was also found normal.

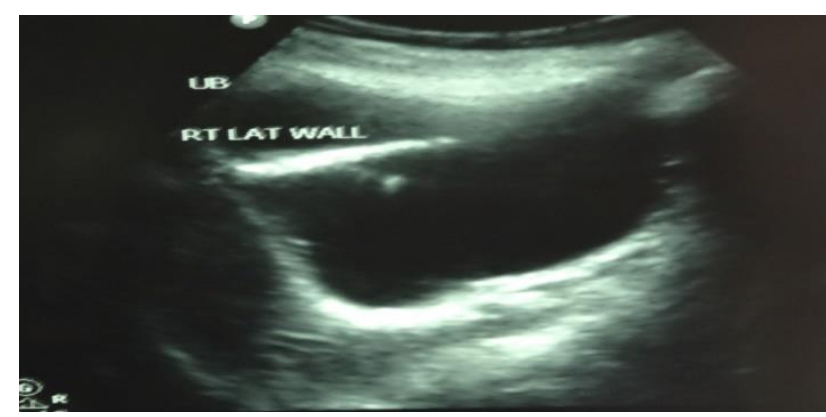

Figure 1A: Ultrasonography of pelvis showing linear echogenic density suggestive of IUCD seen in bladder cavity impacted in right lateral wall. The IUCD is seen perforating the right lateral wall of the bladder.

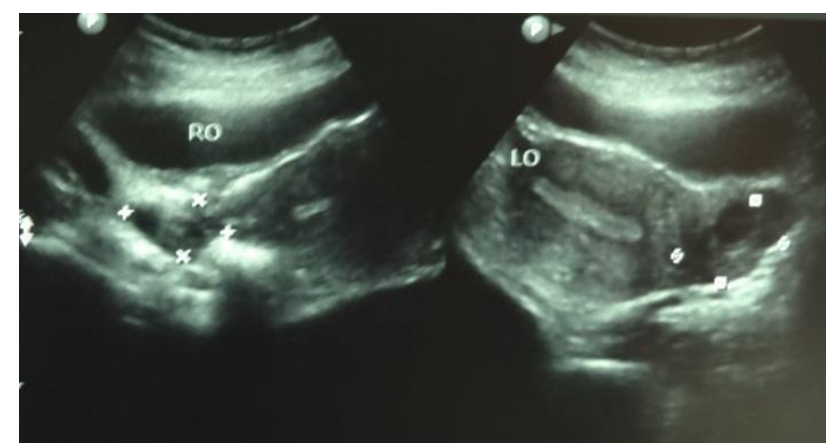

Figure 1B: Transabdominal ultrasonography of pelvis showing uterus with normal endometrial cavity with both normal ovaries. IUCD is not seen inside the uterine cavity.

Ultrasound of the pelvis (Figure 1A, 1B) showed uterus measuring $7.8 \times 4.9 \times 4.2$ centimetres in size with no obvious focal mass lesion was seen. Myometrial echopattern was normal. Endometrial was central and thickness was 8 millimetres. Intrauterine contraceptive device was seen in urinary bladder with lower end impacted in right lateral wall of urinary bladder. Bilateral ovaries were normal in size and position and bilateral adnexa were clear. No free fluid was seen in pouch of douglas. X-ray Pelvis (Figure 2) also showed Intrauterine contraceptive device in lower abdomen which was confirmed on CT urography (Figures 3A-D). Hysteroscopy was done and IUCD was not seen in uterus. Cystoscopic per uretheral removal of IUCD done (Figures 4A-C).

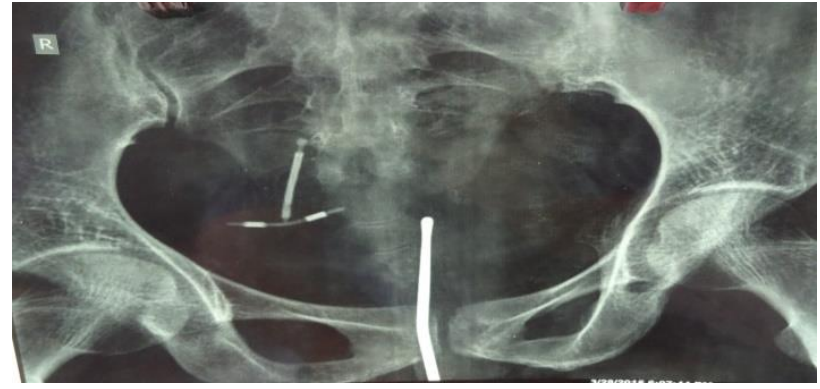

Figure 2: Frontal X-ray of the pelvis with uterine sound kept inside the uterine cavity demonstrates presence of inverted intrauterine contraceptive devices within the pelvic cavity on the right side of sacrum.

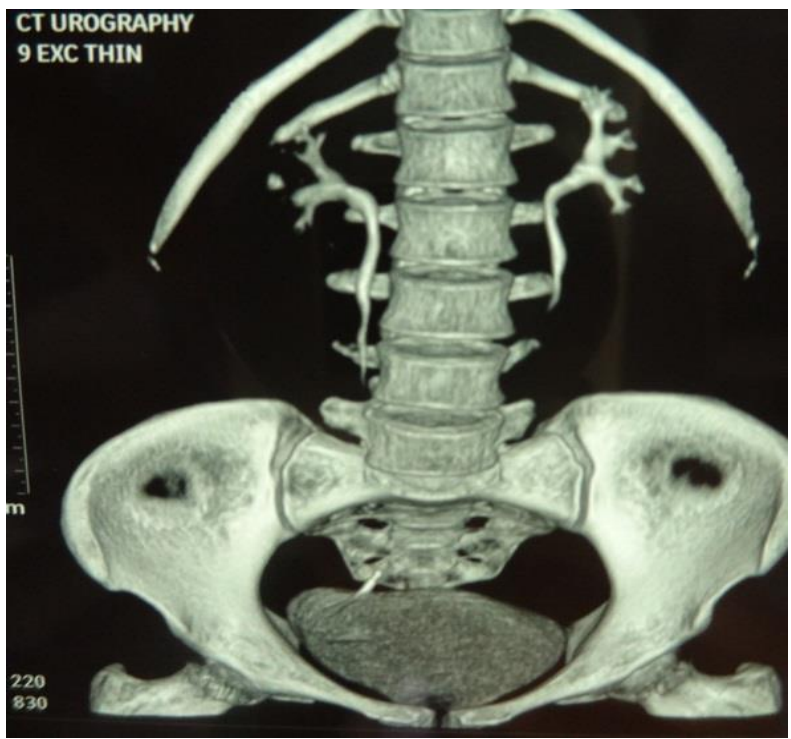

Figure 3A: CT Urography coronal view showing vertical stem of intrauterine contraceptive devices perforating the urinary blabber on right side.

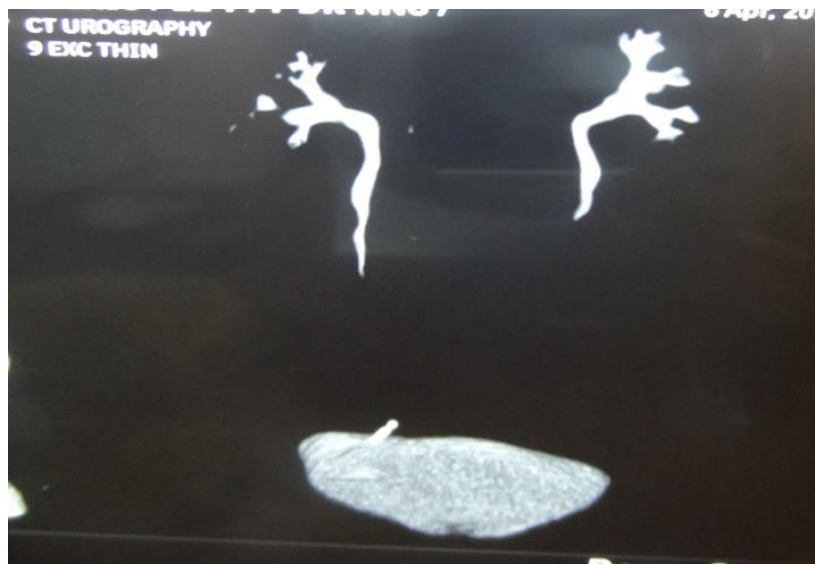

Figure 3B: CT Urography with coronal subtracted view showing normal pelvic calyceal system and intrauterine contraceptive devices perforating the urinary bladder on fundal aspect on the right side. 


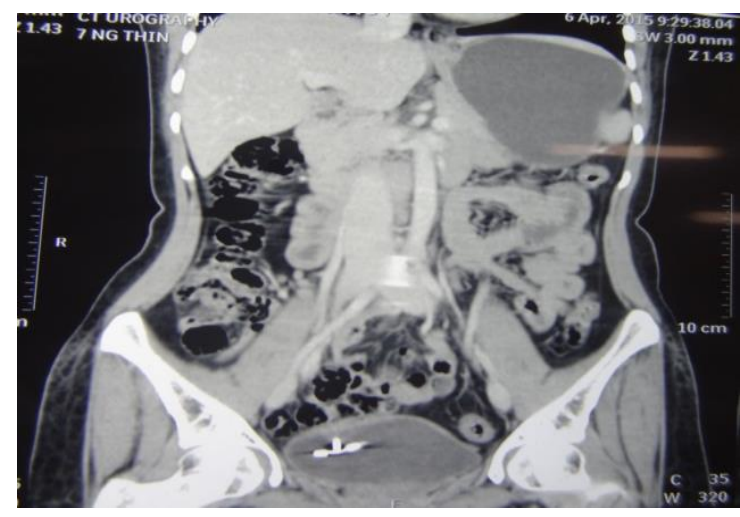

Figure 3C: CT Urography with coronal reconstruction showing horizontal arms and proximal part of vertical stem of intrauterine contraceptive devices seen impacted in the urinary bladder.

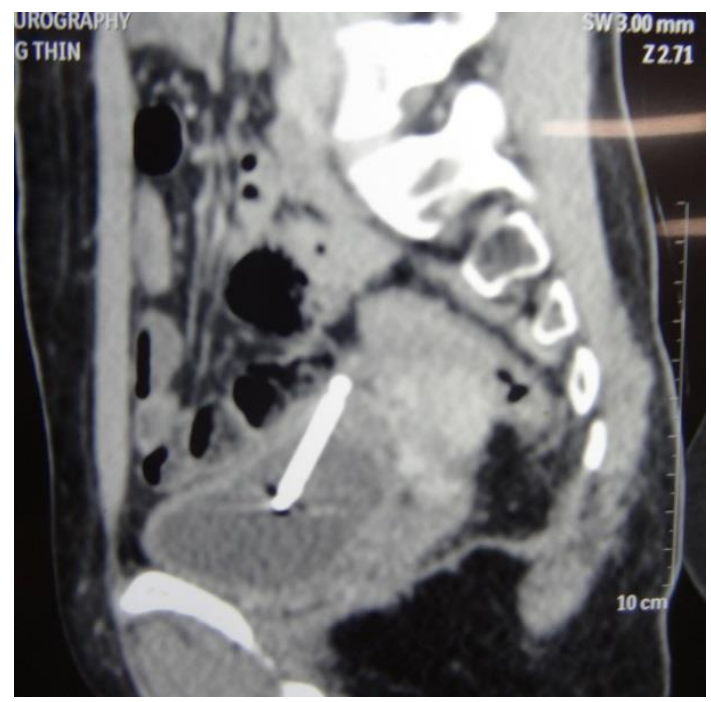

Figure 3D: CT Urography with sagittal reconstruction showing vertical stem of intrauterine contraceptive devices perforating the right lateral wall of bladder.

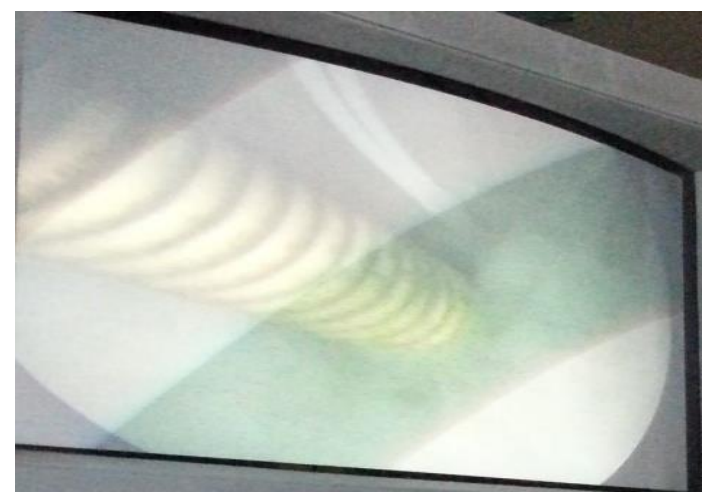

Figure 4A: Per urethral cystoscopy revealed presence of vertical stem of IUCD perforating the urinary bladder. IUCD tail with thread seen impacted in bladder wall.

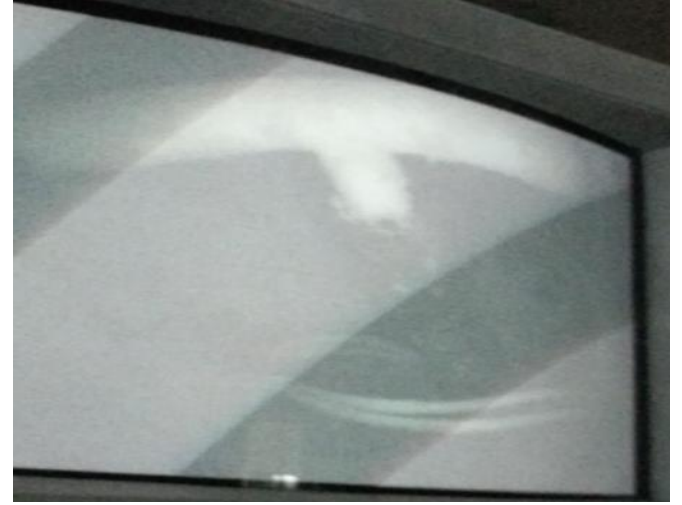

Figure 4B: Per uretheral cystoscopy revealed horizontal arms of IUCD floating in bladder cavity and IUCD tail with thread impacted in right lateral wall of urinary bladder.

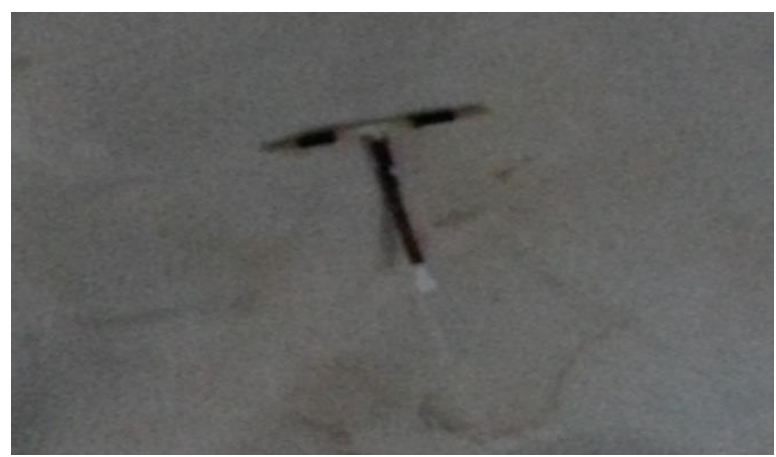

Figure 4C: Per uretheral removal of IUCD (in toto).

Intraoperative findings: On cystoscopic examination there was evidence of IUCD in urinary bladder with horizontal arm in bladder cavity. Lower end of stem along with threads of IUCD was embedded on right superolateral side of the urinary bladder approximately 3 centimeters above right ureteral orifice. Rest of urinary bladder wall mucosa was normal. Cystoscope with assembly introduced and part of IUCD which was embedded in bladder wall disimpacted inside the cavity by stone holding forceps. Complete IUCD with threads removed peruretherally. IUCD was shown to patient and relatives. There was evidence of oedematous mucosa at the site of embedded IUCD. Check cystoscopy was done and $16 \mathrm{Fr}$ catheters inserted per urethra. Intra operative and post-operative period was uneventful. Post-operative urinary catheter was kept for 3 weeks. Patient could pass urine without any difficulty and discharged after 3 weeks. Patient follow up at 3 months revealed complete relief of previous symptoms.

\section{DISCUSSION}

IUCDs have been in wide use since 1965 . $^{2}$ Intrauterine device (IUCD) is among the most effective reversible form of contraception available. The adverse effects associated with IUCD use are expulsion, uterine perforation and migration of the device. Perforation may 
be silent and is either detected after or found incidentally by imaging. IUCD migrations from the uterus occur with a reported incidence of $0.5-1 \% / 1000$ IUCD insertions. ${ }^{3}$ Misplaced IUCDs have been reported from several neighbouring organs such as the intestinal tract, ${ }^{4}$ and the urinary bladder, which lead to the formation of vesical calculi. ${ }^{5}$ They may lead to perforation of the appendix, thus mimicking appendicitis. ${ }^{6}$ They may also be found embedded in the omentum. ${ }^{4}$ They may have been mistakenly inserted into the rectum, ${ }^{7}$ and probably into the urinary bladder, as this case report has suggested.

The mechanism of migration is thought to be the insertion procedure itself or a chronic inflammatory reaction with gradual erosion through the uterine wall. The incidence is influenced by several factors, which include the timing of the insertion, the parity, a history of previous abortions, the type of IUCD which is inserted, the experience of the operator and the position of the uterus. ${ }^{8}$ A delayed onset of symptoms supports a secondary migration. The mechanism of an incorrect placement can only be attributed to an incomplete and faulty training, as well as the reliance of the patients on the untrained or inadequately trained paramedical staff instead of a well-trained doctor/gynaecologist.

An ultrasonography of the abdomen and pelvis is usually the initial examination of choice, for verifying the presence of an IUCD in the pelvis. Once it is found, Xray can be done to determine the location of the IUCD relative to the uterus. The treatment of the misplaced IUCD is surgical, hysteroscopy, laparoscopy or laparotomy. Withdrawal of the migrated IUCD is advisable even if its migration has not given rise to any clinical symptoms, ${ }^{9}$ so that further complications like a bowel and bladder perforation or a fistula formation may be averted.

Patients with misplaced intrauterine contraceptive device (IUCD) may remain asymptomatic for years. ${ }^{10-12}$ In one series of 324 cases with misplaced IUCD in 258 (79.93\%) cases Copper-T was found in the uterine cavity and in 47 cases $(14.51 \%)$ it was removed from cervical canal. In only 18 cases $(5.56 \%)$, it was translocated. ${ }^{13}$ The accepted treatment for displaced IUCDs is surgical removal because of the risk of adhesion formation or of damage to the intestine or urinary bladder. ${ }^{14}$ In a study by Trivedi SS et al on a 38 patients with intrauterine devices with lost strings, hysteroscopic aid was required after routine retrieval procedures failed. Thirty five intrauterine devices could be removed easily with hysteroscope. Laparotomy was required in only one patient, for an extra-uterine Copper-T. ${ }^{15}$

The purpose of this case report was to show that IUCD can be inserted in the urinary bladder if procedure is not done systematically by trained personnel.

\section{CONCLUSION}

In India, it is essential, that every effort should be made to bring down the failure and the complication rates of the contraceptive measures, so that more patients avail of family planning services. An IUCD is a safe method of contraception. The family planning officers should ensure that a mere insertion is not the end point of their services. They should also educate the clients about the potential benefits, adverse effects and the complications of the device. Proper training of the family planning officers and paramedical staff at centres should be ensured so as to provide safe and better family planning services.

\section{Funding: No funding sources \\ Conflict of interest: None declared \\ Ethical approval: Not required}

\section{REFERENCES}

1. Levsky JM, Herskovits M. Incidental detection of a transmigrated intrauterine device. Emerg Radiol 2005;11:312-4.

2. Zakin D, Stern WZ, Rosenblatt R. Complete and partial uterine perforation and embedding following insertion of intrauterine devices. Obstet Gynaecol Surg. 1981;36:335-53.

3. Kriplani A, Garg P, Sharma M, Agarwal N. Laparoscopic removal of extrauterine IUCD using fluoroscopy guidance: a case report. J Gynaecol Surg. 2005;21(1):29-30.

4. Key TC, Kreutner AK. Gastrointestinal complications of modern intrauterine contraceptive device. Obstet Gynecol. 1980;55:239-44.

5. Singh I. Intravesical cu-T emigration: an atypical and infrequent cause of vesical calculus. Int Urol Nephrol. 2007; 39(2):457-9.

6. Carson SA, Gatlin A, Mazur M. Appendiceal perforation by copper-7 intrauterine contraceptive device. Am J Obstet Gynecol. 1981;141(5):586-7.

7. Laxmi M, Hemlata J, Rani LP. An unusual case of copper-T in rectum. J Obstet Gynecol India. 2005;55(1):79-80.

8. Heartwell S, Schlesselman S. Risk of uterine perforation among users of intrauterine devices. Obstet Gynecol. 1983;61:31-6.

9. Treisser A, Colau JC. Causes, diagnosis and treatment of uterine perforations by intrauterine devices. J Gynecol Obstet Biol Reprod. 1978;7:83747.

10. Haimove-Kochman R, Amsalen H, Adoni A, Lavy Y, Spitz IM. Management of perforated levonorgestrel-medicated intrauterine device -- a pharmacokinetic study: case report. Hum Reprod. 2003;18:1231-3.

11. Ismail H, Mansour D. The 'tail' of a missing intrauterine contraceptive device. J Fam Plann Repord Health Care. 2002;28:96-7.

12. Hasanain FH. The misplaced IUCD. Int $\mathbf{J}$ Gynaecol Obstet. 2002;78:251-2. 
13. Barsanul M, Sharma N, Sangwan K. 324 cases of misplaced IUCD: a 5-year study. Trop Doct. 2003;33:11-2.

14. Markovitch O, Klein Z, Gidoni Y, Holzinger M, Beyth Y. Extrauterine mislocated IUCD: is surgical removal Mandatory? Contraception. 2002;66:105-8.
15. Trivedi SS, Goel M, Jain S. Hysteroscopic management of intra-uterine devices with lost strings. Br J Fam Plann. 2000:26:229-30.

Cite this article as: Changede PR, Gupta SS, Chavan NN. Endoscopic retrieval of intrauterine contraceptive device from urinary bladder. Int J Reprod Contracept Obstet Gynecol 2015;4:1593-7. 